\title{
Por uma Educação não sexista contra a neutralidade ideológica de gênero
}

Príscila Carvalbo ${ }^{1}$

RESUMO: Após décadas de plurais engajamentos em defesa de um Ensino crítico, vemos surgir um projeto de lei que afirma falar em nome do direito dos estudantes à Educação com neutralidade e liberdade de pensamento e das famílias em orientar sexualmente seus filhos e filhas. Denominado Programa Escola Sem Partido, tal movimento imputa aos docentes dos diversos segmentos de Ensino "abuso do direito de ensinar", que seria produzido por "doutrinação política", "ideologia de gênero" e falta de "neutralidade". Considerando a Constituição da República e a Lei de Diretrizes e Bases da Educação Brasileira procuro tratar as noções de neutralidade, ideologia, assim como o papel formativo da Educação Formal, dos Estudos de Gênero, da Filosofia e das Ciências Sociais a fim de pensar se há legitimidade em tal de tal movimento. Ao fazê-lo, pretendo ter situado a importância de uma Educação antisexista para a democracia, mostrando que a ideologia de gênero é mobilizada pelo referido movimento.

Palavras-chave: Ideologia de gênero; Educação, Neutralidade, Filosofia e Ciências Humanas.

\section{For a non-sexist education against gender ideological neutrality}

\begin{abstract}
After decades of many engagements in defense of a Critical Education, we witness the rise of a bill that affirms speaking on behalf of the students' rights to Education with neutrality and freedom of thought and of families in orienting their sons and daughters sexually. Called Programa Escola Sem Partido (No-Party School Program), this movement imputed to teachers in the various segments of Education the "abuse of the right to teach", which would be produced by "political indoctrination", "gender ideology" and lack of "neutrality". Considering the Constitution of the Republic and the Law of Guidelines and Bases of Brazilian Education, I attempt to analyze the notions of neutrality, ideology, as well as the formative role of Formal Education, Gender Studies, Philosophy and Social Sciences in order to verify is there is legitimacy in such a movement. In doing so, I intend to have claimed for the importance of an anti-sexist Education for democracy, showing that the ideology of gender is mobilized by the abovementioned movement.
\end{abstract}

Key words: Gender ideology; Education, Neutrality, Philosophy and Human Sciences

${ }^{1}$ UFRJ/ PNPD-CAPES. Endereço eletrônico: ptcarvalho1712@gmail.com

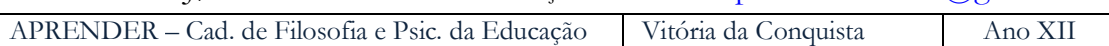


A tese geral deste trabalho se concentra na defesa de que, sob o pretexto de representar neutralidade, defesa da Educação, das famílias e dos(as) estudantes, os argumentos aos quais o Programa Escola Sem Partido recorre para a defesa do Projeto de Lei 7180/2014 demonstra desconhecer e desqualificar o papel da Filosofia, das Ciências Humanas e dos Estudos de Gênero na Educação, passando a interpretar a prática docente e as referidas áreas de conhecimento como antagônicas às necessidades do corpo discente, de suas famílias e da Educação do país. Ao contrário disso, procuro mostrar que a reflexão promovida pelas Humanidades no contexto da Educação Formal é parte, a um só tempo, dos princípios democráticos em vigor na Constituição da República e da formação crítica para o exercício da cidadania, condizente com aqueles princípios. Com isso, sustento que a Filosofia contribui com uma dupla investida para democracia brasileira às quais o Escola Sem Partido, doravante ESP, se opõe de forma ideológica e não neutra, como pretende fazer parecer. Apesar disso, ressalto desde já que tal caráter ideológico dominante talvez não esteja claro para muitos dos seus simpatizantes. Por essa razão são recuperados neste trabalho.

A única aproximação legítima e possível entre os argumentos do ESP com respeito aos valores democráticos quando argumenta que a Escola e as Universidades estariam fazendo ideologia de gênero e doutrinação política ser uma contestação do caráter de "aparelhos ideológicos do Estado"² das instituições públicas, ao qual o ESP, no entanto, não faz qualquer referência ou demonstra conhecimento. Em linhas gerais a condição de "aparelho ideológico de Estado" consistiria na produção e reprodução hegemônica de certos valores e ideias com fim de naturalizá-los para que justifiquem o statu quo sem maiores contestações. Quem faz esse diagnóstico é Louis Althusser acerca do papel ideológico dominante das instituições de Estado. Todavia não é essa a crítica do ESP. Pelo contrário, é fácil e seguro constatar que a atuação dos docentes e dos estudos de gênero justamente questiona a naturalização de valores amparados na Lei de Diretrizes e Bases da Educação 9.394, cuja defesa de um Ensino Crítico converge e dá corpo ao projeto democrático de país expresso na Constituição da República pela primeira vez desde 1988. Sendo assim, o ESP se opõe justamente às problematizações acerca da prevalência de valores ideológicos hegemônicos que sempre atravessaram a Educação. Pelo contrário, procuro mostrar, portanto, que há um alinhamento do ESP com a ideologia antidemocrática, e não com as necessidades de estudantes, de suas famílias e da Educação Formal ofertada pelas instituições públicas, como se segue.

Iniciemos nossa investida lembrando que a Lei de Diretrizes e Bases da Educação Brasileira 9.394, doravante chamada de LDB, é fruto de embates de interesses e ideais para a formação cidadã. Teoricamente, a Constituição Federal de 1988 é liberal, ou seja, não garante propriamente a autonomia estatal e necessidades públicas frente ao mercado econômico. Não obstante, garante alguns direitos

2 Ver ALTHUSSER, Louis, 1971. 
fundamentais e sociais permitindo manter algum horizonte de solidariedade e inclusão social. Valores como igualdade perante a lei e os ideais de liberdade, solidariedade, pluralidade, laicidade, representação, participação, entre outros, garantem seu viés minimamente igualitarista, razão pela qual fora batizada de Constituição Cidadã. Para os presentes propósitos, destaco entre os princípios fundamentais aqueles expressos, respectivamente nos incisos II e V do Artigo $1^{\circ}$, quais sejam, a cidadania e o pluralismo político ${ }^{3}$. Esses princípios são estritamente vinculados aos demais valores acima citados. A aprovação da LDB, e os adendos feitos anos seguintes, está em sintonia com a Constituição e estreita laços entre Educação e desígnios deliberados para o Estado. Se a Constituição define a cidadania e o pluralismo político como princípios, dentre outros, como formar os sujeitos para o exercício da cidadania? Qual o papel da Educação? E dentro dela, que papel tem a Filosofia e as Ciências Humanas? Seriam essas áreas de Conhecimento ideológicas, partidárias ou doutrinárias e, portanto, incompatíveis com o pluralismo de pensamento? E quanto à alardeada ideologia de gênero, seria um fruto perigoso da Filosofia e/ou das Ciências Humanas? Afinal o que é ideologia e o que é ideologia de gênero e qual suas relações com a cidadania e os direitos sociais? O artigo está dividido da seguinte forma: (1) destaque de alguns princípios, fins e aspirações determinados legalmente para o exercício do Ensino Formal e sua consonância com princípios da Constituição Federal, (2) a relação entre neutralidade e ideologia no contexto do papel da Filosofia e das Ciências Humanas na produção do conhecimento e da Educação; (3) Relação entre Ideologia e pensamento crítico e, finalmente (4) a relação entre Ideologia de gênero e uma educação antissexista.

\section{EDUCAÇÃO FORMAL: PRINCÍPIOS E FINS CONSOANTES À CONSTITUIÇÃO FEDERAL}

Os princípios e fins das diversas leis precisam ser consoantes à Carta magna do país para que possam gozar de mínima legalidade e legitimidade. Ao definir princípios e objetivos reguladores de sua organização social, o Estado Brasileiro, por meio de sua Carta Maior ${ }^{4}$, incorpora os valores e ideais que pretende consolidar e/ou construir, declarando em seu preâmbulo:

Estado democrático, destinado a assegurar o exercício dos direitos sociais e individuais, a liberdade, a segurança, o bem-estar, o desenvolvimento, a igualdade e a justiça como valores supremos de uma sociedade fraterna, pluralista e sem preconceito (CF, 1988) ${ }^{5}$

Não por acaso, foi com esse espírito que movimentos docentes e sociais se engajaram ao longo das últimas décadas para que a Educação Formal pudesse incorporar os valores democráticos expressos na Constituição cumprindo seu papel de formação. Direito de todos, dever da Família e do Estado, a Educação envolve diversas relações sociais e familiares, bem como sua oferta Formal, instrutiva, crítica e

\footnotetext{
3 Constituição da República Federativa do Brasil promulgada em 1988. Consultada em 27/11/2018. Disponível em http://www.tse.jus.br/legislacao/codigo-eleitoral/constituicao-federal/constituicao-da-republica-federativa-do-brasil

${ }^{4}$ A Constituição Federal aqui será referida seja como Carta Constitucional, Carta Maior, Carta Magna e Constituição Cidadã e Constituição da República. Em todos os casos me refiro à Constituição de 1988.

5 Constituição da República Federativa do Brasil promulgada em 1988. Consultada em 27/11/2018. Disponível em http://www.tse.jus.br/legislacao/codigo-eleitoral/constituicao-federal/constituicao-da-republica-federativa-do-brasil
} 
reflexiva. Com esse objetivo, formula-se a laica, democrática e plural a Lei de Diretrizes e Bases da Educação Brasileira (LDB) em 1996, e recebe emendas posteriores para se coadunar aos princípios democráticos constitucionais. O fim da LDB é precisamente: a capacitação para o exercício da cidadania, para o desenvolvimento crítico-reflexivo e para o mundo do trabalho, que se consubstancia por meio dos seguintes princípios e bases do ensino

liberdade de aprender, ensinar, pesquisar e divulgar a cultura, o pensamento, a arte e o saber; pluralismo de ideias e de concepções pedagógicas; respeito à liberdade e apreço à tolerância; gestão democrática do ensino público, na forma desta Lei e da legislação dos sistemas de ensino; vinculação entre a educação escolar, o trabalho e as práticas sociais; consideração com a diversidade étnico-racial. (LDB 9.394, Art. $\left.3^{\circ}\right)^{6}$.

Para cada um dos segmentos de Ensino são definidos objetivos. Para o Ensino Fundamental, a LDB prevê que sejam fornecidas as condições para

I - o desenvolvimento da capacidade de aprender, tendo como meios básicos o pleno domínio da leitura, da escrita e do cálculo;

II - a compreensão do ambiente natural e social, do sistema político, da tecnologia, das artes e dos valores em que se fundamenta a sociedade;

III - o desenvolvimento da capacidade de aprendizagem, tendo em vista a aquisição de conhecimentos e habilidades e a formação de atitudes e valores;

IV - o fortalecimento dos vínculos de família, dos laços de solidariedade humana e de tolerância recíproca em que se assenta a vida social (LDB 9394, Art. $\left.32^{\circ}\right)^{7}{ }^{7}$

Para os objetivos do Ensino Médio ficam determinados:

I - a consolidação e o aprofundamento dos conhecimentos adquiridos no ensino fundamental, possibilitando o prosseguimento de estudos;

II - a preparação básica para o trabalho e a cidadania do educando, para continuar aprendendo, de modo a ser capaz de se adaptar com flexibilidade a novas condições de ocupação ou aperfeiçoamento posteriores;

III - o aprimoramento do educando como pessoa humana, incluindo a formação ética e o desenvolvimento da autonomia intelectual e do pensamento crítico;

IV - a compreensão dos fundamentos científico-tecnológicos dos processos produtivos, relacionando a teoria com a prática, no ensino de cada disciplina (LDB9394, Art. $\left.35^{\circ}\right) .{ }^{8}$

Já entre os objetivos do Ensino Superior destaco as seguintes determinações:

I - estimular a criação cultural e o desenvolvimento do espírito científico e do pensamento reflexivo;

III - incentivar o trabalho de pesquisa e investigação científica, visando o desenvolvimento da ciência e da tecnologia e da criação e difusão da cultura, e, desse modo, desenvolver o entendimento do homem e do meio em que vive;

IV - promover a divulgação de conhecimentos culturais, científicos e técnicos que

\footnotetext{
${ }^{6}$ Consultada em 27/11/2018. Disponível em http://www.planalto.gov.br/ccivil 03/Leis/L9394.htm A inclusão da consideração com a diversidade étnico-racial se deu em 2013, através da Lei no 12.796.

7 Lei de Diretrizes e Bases da Educação Brasileira 9.394, consultada em 27/11/2018. Disponível em http://www.planalto.gov.br/ccivil 03/Leis/L9394.htm

8 Lei de Diretrizes e Bases da Educação Brasileira 9.394, consultada em 27/11/2018. Disponível em http://www.planalto.gov.br/ccivil_03/Leis/L9394.htm
} 
constituem patrimônio da humanidade e comunicar o saber através do ensino, de publicações ou de outras formas de comunicação;

VI - estimular o conhecimento dos problemas do mundo presente, em particular os nacionais e regionais, prestar serviços especializados à comunidade e estabelecer com esta uma relação de reciprocidade;

VII - promover a extensão, aberta à participação da população, visando à difusão das conquistas e benefícios resultantes da criação cultural e da pesquisa científica e tecnológica geradas na instituição (LDB 9394, Art. 43º. ${ }^{9}$

Como podemos ver, em níveis distintos, o pensamento crítico e reflexivo sobre a cultura e o mundo faz parte dos eixos definidos para formação cidadã e para a atuação profissional. Além disso, laicas, jovens e democráticas, ambas, a Lei de Diretrizes e Bases da Educação Brasileira e a Constituição da República sinalizam os caminhos para construção de um Estado-Nação soberano, democrático, crítico e socialmente participativo. Não há duvidas que ambas LDB e Constituição Federal, requerem uma formação cidadã crítica capaz de criar uma cultura de valores e instituições democráticos, condições sine qua non para a consolidação e solidez de um país democrático. É a diversidade e pluralidade dos aportes teóricos que formam o arcabouço de uma Educação Formal questionadora, crítica e reflexiva a partir do qual os sujeitos poderão ver e atuar sobre o mundo. Vejamos, então, brevemente no que consistem as ideias de neutralidade, objetividade, ideologia nas áreas da Filosofia e das Ciências Humanas. Em seguida situemos a importância dos questionamentos presentes nos estudos de gênero e sua relação com a ideologia de gênero.

\section{FILOSOFIA, CIÊNCIAS HUMANAS E NATURAIS: POR QUE A NEUTRALIDADE É UM CRITÉRIO IDEOLÓGICO}

Em respeito à tradição de diálogo filosófico com a esfera pública, vejamos algumas palavras do ESP:

No Brasil, hoje, as noções transmitidas de política e cidadania estão flagrantemente contaminadas de conceitos marxistas, particularmente no ensino de nível médio. O que se ensina nas aulas de História, Sociologia, Geografia, e mesmo em Literatura ou Filosofia, não passa de doutrinação.

$\mathrm{Na}$ maioria dos Estados, a rede pública de ensino está sob controle de docentes sindicalistas, militantes partidários. Os textos escolares, quase sem exceção, empregam o vocabulário marxista, mesmo o mais ortodoxo, como "consciência de classe", "luta de classes", "modos de produção", "exploração internacional", "imperialismo americano" e a rotineira demonização do Capitalismo [...] (ESP, 2018) $)^{10}$

O argumento do ESP que fazem menção à vínculos partidários ou ${ }^{11}$ aos conceitos que fazem parte análise materialista como se os mesmos configurassem a substituição de um Ensino nentro por uma

\footnotetext{
9 Lei de Diretrizes e Bases da Educação Brasileira 9.394, consultada em 27/11/2018. Disponível em http://www.planalto.gov.br/ccivil 03/Leis/L9394.htm

${ }^{10}$ Nelson Lehmann da Silva. Educação x Doutrinação. Disponível em http://escolasempartido.org/artigos-top/173-adoutrinacao-ideologica-nas-escolas.

${ }^{11}$ Não caberá aqui tratar do argumento que toma a condição de filiação partidária ou de sindicalização de docentes como desqualificação moral comprometedora da atuação profissional, uma vez que, diferente disso, se trata de um direito político de exercício da cidadania, o qual todos podem ter acesso.
} 
doutrinação partidária soma-se à acusação de que as reflexões sobre a relação entre sexo, gênero e sexualidade romperiam a devida neutralidade e, com isso, configurariam ideologia de gênero. Para nos concentrarmos nesses dois argumentos, que criaram a tensão na esfera pública tentando pôr a Educação no banco dos réus ou como inimiga das famílias, vejamos antes como subjaz em ambos uma visão sobre metodologia cientifica que resulta em hierarquização entre Ciências Humanas, Filosofia e Ciências Naturais. Uma comparação simplória sobre o status atribuído às ciências naturais, biomédicas ou tecnológicas e a desqualificação destinada às Ciências Humanas e à Filosofia pode nos permite perceber que a postura de leigos(as) ao se depararem com temas considerados controvertidos nas primeiras ciências não resulta em desqualificação das mesmas ao passo que ao se referir às controversas temáticas das Humanidades se atribui "subjetiva" e "falta de neutralidade". Talvez haja aí uma dinâmica de aspecto positivo: a aproximação informal entre os temas das Humanidades e o chamado Senso Comum, por se referirem à busca de sentido e de explicações para valores, ideias, pensamentos e fenômenos sociais e/ou existenciais propriamente humanos, autoriza a todos falar com propriedade. A incongruência é que desse fato não decorre a conclusão sobre a importância dessas áreas de conhecimento por tomarem como pesquisa a dimensão e condição propriamente humana. Pelo contrário, o fato de que todos possam pensar e falar sobre várias das questões tematizadas pelas Ciências Humanas e pela Filosofia - já que, em última instância, dizem respeito ao fazer humano - parece dificultar a percepção de que há abordagens metodológicas, analíticas, críticas e reflexivas quando essas questões são convertidas em análise de trabalho. Isso acontece, inclusive, porque a relação do ser humano com o mundo, com os fatos, com o "real", o "natural", o "social” não é acessível sem mediações. Não acessamos o real por osmose, sem gasto energético. Há uma atividade em curso para isso e ainda que a mesma seja imperceptível para alguns resulta em uma visão das coisas. Nossa interpretação faz uma mediação das experiências e influências diversas que nos constituem individualmente e coletivamente e cria sentidos para o real. O ser humano enxerga e concebe o natural à luz de seu discernimento, que, por sua vez, se desenvolve à luz das informações e do desenvolvimento do senso crítico, ou ausência desses. As áreas de conhecimento responsáveis por nos ensinar a habilidade de refletir sobre essa mediação e atribuição de sentidos são justamente as Ciências Humanas e a Filosofia. Ainda que haja objetivos outros, essa é sua vocação. O que nos leva a concluir que os acúmulos, embates e elaboração intelectual são eles próprios temas de pesquisa para as Humanidades, sobretudo os critérios de neutralidade, objetividade e ideologia em questão neste artigo.

Em sua origem moderna, a neutralidade é entendida como critério epistemológico e ético cuja função seria garantir objetividade e universalização. Quando a ideia de cientificidade se sustenta a partir da matematização e da experimentação, características decorrentes da substituição da física aristotélica pela física galileana ${ }^{12}$, as ideias de neutralidade e a objetividade pressupõem que não haja qualquer relação

12 A física aristotélica operava com a ideia de qualidade, ao passo que a física galileana passa a operar com a ideia de quantidade, tomada como sinônimo de rigor científico. 
com os fenômenos estudados. Entender introdutoriamente como esse critério passou a ser visto como condição para a noção de objetividade, e em que contexto epistemológico ele recebe validade, nos vacina contra seu uso ou convocação equivocada. Quando se apela à neutralidade no contexto das humanidades, na forma como o faz o ESP, se ignora, ou pretende que seja ignorado, o fato de que houve uma escolha no trato metodológico utilizado, não é algo necessário e inescapável. Inicialmente destinada aos estudos dos fenômenos da Física a ideia de neutralidade foi estendida às demais áreas do conhecimento. Isso ocorre quando David Émile Durkheim, seguindo o criador da Sociologia, Auguste Comte ${ }^{13}$, propõe estudar os "fatos sociais" adotando a metodologia que a Física utilizava para estudar "fatos naturais". Problematizando essa aplicação indevida, no final do século XIX, Wilhelm Dilthey cria o método Historicista pela distinção entre fatos naturais, regidos por uma ordem natural necessária, e fatos humanos, históricos, movidos por finalidades, sentidos e escolhas. Para serem compreendidos, os fatos precisariam, então, serem vistos sob a ótica de sua dinâmica, isto é, com a adoção de uma metodologia semelhante ao seu funcionamento. Apesar de trazer considerações indispensáveis para repensar as metodologias nas Humanidades, outros teóricos encontram no Historicismo uma extrema relativização e uniformização dos fatos devido à perspectiva historicista de "fases e causas universais". Apesar da crítica importante o Historicismo conservaria do positivismo de Durkheim o tratamento subordinador dos fatos sociais à interpretação progressivista. Nesse debate encontramos, ao longo do século XX, três críticas que caracterizaram a complexidade e riqueza das Ciências Humanas: a Fenomenologia, o Estruturalismo e o Materialismo Histórico. Promovendo fortes revoluções epistemológicas, essas perspectivas analíticas, cada uma a seu modo, propõem que o ser humano e suas relações e experiências sejam compreendidos em suas dimensões e complexidades histórica, cultural, psicológica e social, e não reduzidas a uma dessas. Nenhuma delas pressupõe a completa separação do sujeito e do objeto de estudos, como presume o ponto de vista neutro-objetivo. A neutralidade é, assim, no contexto das Humanidades, tratada por muitas das abordagens como uma dimensão mítica, de uso ideológico, sem qualquer possibilidade de se manter em termos de facticidade concreta. Em outra oportunidade, ${ }^{14}$ analisei o critério de neutralidade enquanto expressão da razão normativa, conforme formulada pela ética kantiana ${ }^{15}$. Naquele caso, resumidamente, neutralidade se tornava quase sinônimo de "ponto de vista moral" implicando o isolamento das influências sensíveis, consideradas comprometedoras da extensão (leia-se possibilidade de universalização) do juízo moral. Sem neutralidade na formulação do juízo moral geraríamos tratamentos assimétricos em relação aos membros da comunidade moral e, portanto, o exercício da eticidade estaria comprometido. Naquele contexto de investigação ética argumentei que a neutralidade se mostra comprometedora, dentre outras razões, por tentar isolar os contextos situacionais concretos que permitiriam a visão da situação cuja demanda ética se quer analisar e sobre a qual se

\footnotetext{
${ }^{13}$ Com posições e contribuições diferentes, Max Weber e o filósofo Karl Marx foram igualmente importantes para a Sociologia.

14 Ver CARVALHO, Príscila, 2015.

15 Ver KANT, Immanuel, 1960.
} 
pretende deliberar. No presente contexto epistemológico-educacional, sinalizo que a neutralidade almejada pelo cientificismo, e pelo senso comum do ESP, é uma ilusão, ou um uso ideológico, que em nada contribui para a cientificidade das ciências humanas ou para a Educação. Quem investiga os fenômenos humanos e o ser humano não pode se deter em cálculos simplistas ou simplificadores, pois a abertura humana infinita, os desejos, interesses e fins humanos escapam a qualquer exame cientificista. Além disso, corroboro com os críticos do século XX em sua afirmação de que os fatos sociais são dinâmicos. A ideia de quantidade - para pensarmos em matematização e controle dos fenômenos - não se torna uma variação da qualidade, mas parte de uma base metodológica cuja fixidez não tem como acompanhar a dinâmica do fazer humano e, portanto, dos tais "fatos sociais". Sendo qualitativa, isto é, variando em termos de possibilidades, as experiências humanas apresentam resultados nada profícuos se conduzidas de modo reducionista, conforme se procurou fazer com a tentativa de aplicação da metodologia das Ciências da Natureza nas Ciências Humanas. Tal intento é apontado como cientificismo positivista. Sendo uma perspectiva ideológica, a neutralidade é base das abordagens tecnocráticas que prevalecem no século XXI. Deixar de apontar essa complexidade na educação significa abdicar de um ensino voltado para a maioridade intelectual, essa sim referência feita por Immanuel Kant que procuro endossar, ainda que em outros termos. O apelo à neutralidade, portanto, dissimula diversos objetivos ideologicamente não declarados, entre os quais a existência de finalidades e prioridade de investimento destinado para algumas pesquisas em detrimento de outras para sustentar a manutenção de certos paradigmas, que resultam em anteparo a determinados valores e comportamentos sociais. Posto isso, sustento que a história do pensamento nos mostra que a neutralidade não pode ser tratada como sinônimo de isenção ou ponto de vista científico ou moral.

\section{IDEOLOGIA DOMINANTE X PENSAMENTO CRÍTICO}

É nuclear, na ideologia, que ela possa representar o real e a prática social através de uma lógica coerente. A coerência é obtida graças a dois mecanismos: a lacuna e a "eternidade". Isto é, por um lado, a lógica ideológica é lacunar, ou seja, nela os encadeamentos se realizam não a despeito das lacunas ou dos silêncios, mas graças a eles; por outro lado sua coerência depende de sua capacidade para ocultar sua própria gênese, ou seja, deve aparecer como verdade já feita e já dada desde todo o sempre, como um "fato natural" ou como algo "eterno". (CHAUí, Marilena, 2016).

O pensamento ideológico dominante não admite Filosofias ou críticas. Todas às vezes, ao longo da História, em que um conjunto de ideias que coopera em favor da manutenção do status quo foi questionado operou-se, junto com a força bruta, uma resposta mobilizando pré-conceitos e desinformações para sabotar os questionamentos. Mas o que seria ideologia, e por que razão o ESP atribui aos docentes, à Filosofia, às Ciências Humanas e, em particular, aos Estudos de Gênero, uma condição de doutrinação ideológica e abuso do direito de Ensinar? 
O conceito de ideologia fora empregado pela primeira vez pelo francês Destutt de Tracy em sua obra Élements d'ideologie (entre 1801 e 1805) que trata da produção do conhecimento. Até aquele momento, a noção de ideologia era apresentada publicamente como uma perspectiva analítica das ideias tanto por Destutt como pelos demais ideólogos franceses. Politicamente, os ideólogos defendiam os ideais em favor das mudanças prometidas por Napoleão Bonaparte contra a monarquia e o poder teológico na política, tendo contribuído indispensavelmente para a aprovação da Educação Pública Nacional naquele período revolucionário. Todavia, ao questionarem determinada posição de Bonaparte, sobretudo no tocante à segurança, os ideólogos foram estigmatizados. No discurso no Conselho de Estado em 1812, Bonaparte afirmara que as mazelas da legislação francesa padeciam da visão "metafísica" dos ideólogos, algo que muitos consideram que não encontrava facticidade no caso da França. Na Alemanha de 1845, na obra $A$ ideologia Alemã (2007), o filósofo Karl Marx utiliza esse mesmo sentido pejorativo de ideologia para se referir à tradição alemã da filosofia idealista. Ali, e em outras obras, Marx falará sobre o papel da ideologia dominante na economia e no pensamento filosófico da Alemanha. Para Marx, a corrente de pensamento chamada de idealismo estrutura uma visão dialética que inverteria a relação entre as ideias e o real, fazendo parecer que a realidade material é fruto de nossos ideais compartilhados quando, para a análise materialista dialética histórica, as condições materiais engendram os valores que devem ser disseminados para manter tais condições sem questionamentos que a abalem. Mais uma vez aqui poderíamos ser levados a pensar que os argumentos do ESP se aproximam, ironicamente, da perspectiva crítica marxista ao se referir à ideologia. Seria esse o caso? Longe disso. Apesar de ser entendida como "falsa consciência", conforme aponta Karl Marx, a ideologia, quando em seu uso pejorativo, passa a ser compreendida como conjunto das ideias predominantes e com desdobramentos políticos de certa época para manter certo estado de coisas materiais a partir da alienação. Contudo, nesse caso a ideologia dominante seria o problema quando promovesse a interpretação acerca da relação entre ideias e poder econômico, que impediria o sujeito de perceber seu lugar e função de explorado no contexto. A influência da penetração da ideologia dominante implica, ainda, em reprodução de valores que atendiam à manutenção de certa condição e organização social. Para entendermos melhor o argumento, pensemos na etimologia da palavra ideologia: o estudo, análise ou pensamento (do grego logos/logia) sobre as ideias ou, ainda, um conjunto de ideias que compõe uma visão de mundo ideal a ser alcançada. A ideologia dominante, nesse caso, operaria de forma que não se percebe de onde parte sua influência e interesses, como a filósofa Marilena Chauí (2016) a define na citação no início desta sessão. Observemos a partir dessa menção algo muito importante que nos permite diferir o uso e caráter nocivo ou democrático da ideologia. Sendo dominante no contexto acima, a ideologia não se declararia como um ideal ou assumiria valores ou causas como objetivos finais. Bastante diferente de uma visão idealista, na qual é declarado e defendido um projeto ou uma concepção, a ideologia dominante se pauta sempre na pré-reflexão, preconceitos e dogmatização de valores e oculta objetivos. É dessa forma que ela se mantém forte e operante: camuflada em defesas plausíveis oculta de parte dos que a ela recorrem desavisadamente os propósitos de poder que a mobilizam. A ideologia dominante se apresenta 
operante tanto no imaginário social popular como em algumas linhas de força teórica desdobradas no campo legal e institucional. Onde quer que haja ideologia dominante haverá uma forma de organizar os valores e processá-los para que os mesmos sirvam a um determinado fim político e econômico não declarado. Esse é o problema com a ideologia dominante: não estamos falando de ideais legitimamente declarados e defendidos, mas de meios de manipulações camuflados de neutros. É neste ponto que a neutralidade se encontra mais evidentemente com a ideologia dominante.

Torna-se irônico que o sentido ao qual o ESP recorre para desqualificar o que seria a doutrinação ideológica é justamente aquele atribuído por Marx, autor mitificado pejorativamente pelo ESP. Mais irônico ainda que a noção de neutralidade à qual recorre o ESP seja exatamente aquela que se converte em recurso ideológico que obscurece a relação entre conhecimento, valores, interesse político, materiais e visão de mundo. Posto isso, não caberia nem se sustentaria a caracterização das perspectivas teóricas e práticas pedagógicas de intelectuais-professores(as) como doutrinárias. Diga-se de passagem, tampouco essas perspectivas críticas compartilhadas entre docentes e intelectuais são idênticas. Para sermos precisos, podemos caracterizá-las, em sua maioria, como contra-hegemônicas. Nesse caso, docentes cumprem um papel de formação crítica da cidadania que, conforme expresso pela LDB: buscar tornar cidadãs e cidadãos aptos a refletir sobre os fenômenos da cultura e da política. Tampouco a Filosofia ou as Ciências Humanas podem ser consideradas doutrinas, sejam partidárias ou apartidárias. Doutrinas conformam dogmas, ou seja, visões de natureza irrefutáveis, no sentido de sua impossibilidade de serem postas à prova ou debatidas. Nesse sentido dogmas podem ser ao menos de dois tipos: os de caráter religioso quando suas verdades se ancoram no campo das verdades ditas reveladas - ou quando se apresentam como visões, seja do senso comum seja de teorias que não se põe à prova ou não se deixam problematizar, como é o caso das ideologias dominante, a exemplo do familismo ocultado pelo ESP. Dogmas precisam naturalizar ou atribuir caráter sobrenatural de forma inalcançável para tornar seus pressupostos intocáveis e não questionáveis. O caráter não problematizável de um conjunto de ideias ou visão o torna um dogma. Ser dogmatikós se faz ao alimentar uma visão dogmática, isto é, não problematizadora do real. Suas ideias assumem a forma da necessidade, do que acontece necessariamente, como na dimensão natural da vida. Nesse caso se diferencia da dimensão da liberdade, isto é, do devir, das escolhas ou das convenções deliberadas que caracterizam os pensamentos, ideias, teorias. Sejam irretocáveis pela força de sua consistência ou inconsistentes, ideias só se converter em dogmas se perdem sua força analítica, reflexiva e crítica.

Tendo a Filosofia uma dimensão polifônica voltada para as dimensões do estar, ser e fazer humano, bem como para seu próprio exercício de reflexão, não se transforma em dogma ou doutrina seja porque, como afirma Karl Japers, está “em contínua pugna consigo mesma” (JASPERS, 1971), seja porque olha o mundo em pesquisa participativa habitando-o dialeticamente. Não obstante, o descarte da lente dogmática ou doutrinária pode ou não levar a Filosofia para o extremo oposto, a saber, a paralisia cética que se põe tartamuda ou, ainda, sem palavras diante do mundo. No mais das vezes, a Filosofia não 
se furta a falar por ser no diálogo que se constrói sua peculiaridade e contribuição. Entre dogmas doutrinários e incapacidades céticas de análise ou ausência de reflexão, que se mostram formas diferentes de negar o mundo, a Filosofia procura assumir sua função de pensar seu tempo e a si mesma, assumindo sua dimensão propositiva. A forma como a reflexão se relaciona com o mundo pode implicar a forma como o ser humano se relaciona consigo mesmo ou pensado de outro modo, como argumenta o filósofo Gerd Bornheim em Introdução ao Filosofar (1989), haveria um paradoxo na situação humana em precisaria sair do mundo para adentrá-lo. Penso esta saída como o distanciamento participativo, não como uma abdução neutra e desincorporada. Nesse sentido, podemos afirmar que a teoria marxista - tão mitificada e endemonizada pelo ESP - é apenas uma dentre tantas análises filosóficas, não obstante sua potência indispensável de pensamento. Um de méritos é ter problematizado o caráter ora ingênuo ora ideológico das Ciências Humanas e da própria Filosofia, evidenciando as relações entre as ideias, os modos de produção, o poder econômico, as instituições sociais, a exploração da força de trabalho das pessoas, etc. Nesse sentido, mais uma vez se torna irônico constatar que poderia o ESP ter corroborado as ideias de Marx ao questionar uma ideologização doutrinária das ideias e do ensino não fosse sua inconsistência e a tentativa ideológica de se opor à formação democrática e critica as reais bases desse movimento. A contribuição daquele filósofo não impede que aspectos diversos de seu arcabouço seja posto à reflexão, como é o caso, por exemplo, da análise sobre a mais-valia do trabalho, que teóricas feministas estenderam ao trabalho doméstico não remunerado das mulheres em sua condição de subalternização. ${ }^{16}$ Ainda que indispensável no que se propõe a fazer, o chamado legado teórico marxista, em suas limitações e em sua capacidade de análise abrangente, é tão importante para a análise e formação crítica da cidadania como deve ser sujeito à críticas. Cada perspectiva analítica tem sua contribuição singular, o marxismo é indispensável em seus propósitos, assim como o são o estruturalismo, o pós-estruturalismo, o póscolonialismo, o decolonialismo, a fenomenologia, o existencialismo, a Teoria Crítica, o Existencialismo, a psicanálise, a antropologia filosófica, as Teorias Feministas, as Teorias e Estudos de Gêneros. Os aportes teóricos e analíticos das Ciências Humanas e da Filosofia constituem as contribuições críticas a partir das quais podemos descortinar conexões até então invisíveis para o olhar ingênuo que acredita que o real se explica a si mesmo. A redução da Filosofia e das Ciências Humanas a uma ideologia, conforme o ESP induz a opinião pública a pensar, implica desonestidade intelectual flagrante e uma estrutura discursiva, ela sim, ideológica no sentido pejorativo do conceito, porquanto oculta que sobrevive na defesa da neutralidade para não explicar ao que veio. Pensar a relação entre neutralidade e valores da ideologia dominante é um dos objetos de investigação dos Estudos de gênero que nos permitirá avaliar o papel que cumpre os Estudos de Gênero na formação cidadã.

\footnotetext{
${ }^{16}$ Não é objetivo deste trabalho analisar essa temática, apenas destacar que são instituições sobre as quais temos uma visão nem sempre aprofundada.
} 


\section{IDEOLOGIA DE GÊNERO: O QUE É E O QUE DIZEM QUE SERIA}

O sexo é, ao contrário, o elemento mais especulativo, mais ideal e igualmente mais interior, num dispositivo de sexualidade que o poder organiza em suas captações dos corpos, de sua materialidade, de suas forças, suas energias, suas sensações, seus prazeres. FOUCAULT, [1976], 1988, p. 145.

A Fome é a fome, mas o que conta como alimento é algo culturalmente definido e adquirido. Toda sociedade tem alguma forma de atividade econômica organizada. $\mathrm{O}$ sexo é o sexo, mas o que conta como sexo é algo culturalmente definido e adquirido. Toda sociedade também tem um sistema de sexo/gênero - um conjunto de disposições pelas quais a matéria-prima biológica do sexo e da procriação humana é moldada pela intervenção humana, social, e satisfeita de uma maneira convencional, por mais bizarras que sejam algumas dessas convenções. GAYLE RUBIN, [1975] 2017, p.17.

Quando se nomeia de ideologia de gênero as problematizações sobre as relações de poder em torno do sexo, o gênero e a sexualidade se oculta que essas análises justamente investigam o viés ideológico de gênero, que a propósito sempre esteve presente na História da Educação: tanto nos livros didáticos como nas relações e orientações que predominam na escola desde a mais tenra infância escolar. A própria formação curricular dos docentes era, e ainda o é um tanto, atravessada por esse mesmo viés. Se quisermos falar honestamente sobre ideologia de gênero não podemos ocultar ou negligenciar esse documentado viés ideológico. Amparando a manutenção das disparidades sociais entre homens e mulheres, os valores se mantiveram hierárquicos e sexistas sem qualquer contestação aceitável, tendo a Escola um papel de destaque para mantê-los longe de qualquer problematização. Nenhuma reação surgiu daqueles que concordavam ou se beneficiavam com tal situação. Pelo contrário, muitas das inúmeras contribuições da Filosofia canônica, ainda que riquíssimas em outros aspectos coadunavam-se com tal ideologia e jamais foram acusadas de ideológicas. Senão vejamos alguns exemplos.

Na obra Emílio (1762), de Jean-Jacques Rousseau a defesa de um modelo de Educação diferenciado para mulheres e homens em que para Emílio caberia uma Educação iluminista e emancipatória e para Sofia era prescrita a tarefa de se qualificar para melhor cuidar e servir. É lamentavelmente incoerente que um filósofo democrata, referência do pensamento republicano, pudesse se valer de uma concepção sexista, por isso mesmo é antidemocrática. A publicação da filósofa Mary Wollstonecraft de $A$ Vindication of the right of men (1792), contesta a segregação das mulheres de seu direito à instrução, defendendo que as mesmas não poderiam ser destinadas a companhias masculinas. Wollstonecrafto defende que para se tornarem sujeitos de suas vidas a igualdadade de direitos seria indispensável. Não por acaso Wollstonecraf formula a questão da educação como condição para liberdade e igualdade. Sua obra influenciaria todo o feminismo no século XIX, sobretudo o liberal. Contudo, até pouco tempo não se lia a crítica da filósofa, sendo apresentado às docentes em formação apenas Emílio, sem questionamentos. Nesse contexto espanta que a apresentação necessária da obra de Mary Wollstonecraft para a formação docente seja rotulada de ideologia de gênero? Como justificar tal disparidade de tratamento quando as críticas de Wollstonecraft são absolutamente congruentes com a 
democracia, com os direitos civis e os propósitos da LDB?

Outro exemplo encontra-se nas promessas da revolução francesa, amparada pelo projeto filosófico moderno iluminista que atribuía à razão a libertação e emancipação humana sobre os preconceitos e condicionamentos dos obscurantismos medievais. No entanto se constata que a suposta cultura emancipatória se destinava somente a alguns. Tanto assim que após lutarem juntos, mulheres e homens, a supremacia dos últimos e a subordinação e subalternização das primeiras se mantém. Um exemplo paradigmático dessa descrição dos fatos é a circunstância que envolve a primeira formulação do que, mais tarde, se tornou a Declaração dos Direitos Humanos, inicialmente intitulada Declaração dos Direitos do Homem e do Cidadão. Supostamente neutra a palavra homem contemplaria racionalmente a humanidade em uma mágica conceitual ideológica. Em resposta, considerando a subalternização das mulheres incompatível com as promessas da revolução, Olympe de Gouges escreve a Declaração dos Direitos da Mulher e da Cidadã (1791), inicialmente ridicularizada. Naquele contexto revolucionário fica evidente que a ideologia de gênero não é um atributo somente do pensamento conservador, embora o seja predominante. A ideia segundo a qual as mulheres se emanciparão se a classe trabalhadora deixar de ser explorada, como pensam os marxistas ortodoxos, não resolve nem erradica automaticamente o androcentrismo, cujas bases não se encontram somente na condição de classe das mulheres. As bases que o sustentam são mais complexas e extrapolam a exploração de classe como tratada pelo materialismo ortodoxo, o que faz improcedente e confusa a argumentação do ESP juntando sem reservas análises marxistas e teorias de gênero como se não houvesse embates, trocas e diálogos, entre ambos. O entendimento de que há um sistema de gênero em qualquer parte do mundo e de que o mesmo não se erradica automaticamente no caso de um modo de produção socialista que não se proponha a isso é um ponto inegociável para a maior parte das teóricas feministas, muito embora seja preciso consentir que a defesa de um modo de produção justo seja algo ideal para a erradicação das diversas injustiças sociais.

É nesse âmbito que compreender a natureza do sexismo masculinista, verdadeira ideologia de gênero, é importante para a formação cidadã. Pensar o conceito de gênero faz parte desse processo, ainda que também ele seja objeto de questões. Tal compreensão nos permite evidenciar a existência de uma estrutura cultural e educacional baseadas no imaginário estético, moral e epistemológico formado por hierarquias entre homens e mulheres ${ }^{17}$ que podem e devem ser alteradas, ou como explica Gayle Rubin: "Um sistema de sexo/gênero [...] se refere a essa esfera de relações, e indica que a opressão não é inevitável nessa esfera, mas éproduto das relações sociais específicas que a configuram". (1975, p.8-9). Problematizar o gênero e os papéis sociais permite também evidenciar componentes epistêmicos, políticos e legais que mantém o binômio mulher-homem como estrutura de atribuição de status especial para os que são representados como sujeito universal e neutro. A manutenção da dualidade se dá como manutenção do antagonismo,

\footnotetext{
${ }^{17}$ Para os propósitos presentes, afirma-se que o androcentrismo afeta qualquer performatividade dentro e fora desse universo binário. Pessoas que não correspondem às adequações normativas desse binarismo também serão objetos de desprestígio, e terão negados direitos atribuídos aos demais cidadãos, inclusive o da vida em segurança.
} 
não somente como descrição de diferenças. As diferenças, nesse caso, são marcadas hierarquicamente e transformadas em questão de valor. Mantidas como pré-discursivas, são, todavia articuladas no campo da produção de sentido e da linguagem. Uma dessas hierarquias se sustenta na suposição de estabilidade, "coerência" e correspondência entre o sexo com o qual se nasce com um determinado gênero e uma determinada sexualidade. Por essa razão, quando os estudos de gênero questionam essa estrutura não querem dizer que haja algo de errado em estar de acordo com esse esquema biopolítico como uma opção possível. Ser heterossexual não é algo reprovável, como não deveria ser qualquer outra conformação ou performance sexual. Entretanto, saber que a correspondência acima é uma construção normativa sociocultural e não um imperativo da natureza em nós é não apenas um direito de todos e todas, mas uma reflexão legítima e urgente, pois o sexo, o gênero e a sexualidade são tornados objetos de disciplina e vigilância dos comportamentos e incorporados por cada pessoa a partir de uma tecnologia biopolítica na qual a vida, e em especial a sexualidade, torna-se matéria e mecanismo político. Como exercer cidadania sem tal consciência? Como mostra o filósofo francês Michel Foucault em História da Sexualidade (1988), duas seriam as estratégias do biopoder. A primeira centra-se no corpo, concebendo-o como máquina: adestra-o, torna-o útil e dócil, através das disciplinas anátomo-políticas. Ao passo que na segunda estratégia, o corpo é a configuração à luz de seu pertencimento na espécie. Nesse caso, regulam-se os nascimentos, a longevidade, a saúde. À luz da leitura de Foucault, estendendo e complexificando suas análises, a filósofa estadunidense Judith Butler, tornada objeto da cultura do ódio dos seguidores do ESP, se debruça sobre o universo do binarismo de gênero e de sexo, dando àquelas, novos aportes e questões. Em especial, sobre o exame da relação entre sexo e gênero, Butler sustenta que "A hipótese de um sistema binário dos gêneros encerra implicitamente a crença numa relação mimética entre gênero e sexo, na qual o gênero reflete o sexo [...]” (2010, p.24-25). Digo de outro modo, a manutenção de normas sociais a partir do uso da Biologia (e, acrescento: da religião) faz dessa a intérprete da natureza para fins de justificação dos valores sociais e nos converte em fiscais da sexualidade e da performance de gênero das pessoas à volta.

Pelas razões expostas, temos que estar cientes de que se nossa produção teórica e educacional não problematiza essa dimensão da cultura e os ditames das formas pré-fixadas de estar no mundo, não poderemos dizer que temos uma Educação propriamente democrática e/ou condizente com os valores expressos na Constituição e na LDB. A fixidez fictícia introjetada como um ditame da natureza significa impor a algumas pessoas que se sintam, sejam vistas e tratadas como abjetas, como fora da curva da normalidade ou como subalternizáveis. Manter uma educação sem tais problematizações fetichiza e mitifica o reino natural, assim como a variação de sexo e de comportamento do reino animal humano e não-humano. Diferente disso, vimos que pensar sobre a forma como o ser humano está no mundo é parte indispensável da formação crítica para a cidadania e para a capacidade de autodeterminar-se. Tanto as práticas sociais como a reflexão sobre a relação entre o mundo da natureza (physis) e da cultura (nomos) fazem parte da Educação. As reflexões acerca da dimensão política e biopolítica da sexualidade e do gênero já não podem mais ser contidas ou evitadas, pois as mesmas vêm sendo usadas de forma que a 
construção da subjetividade, a possibilidade de florescimento humano e o alcance da justiça social são afetados. É preciso assumir que evitá-las ou contê-las significa usá-las como violadores dos direitos humanos, como deixam evidentes as estatísticas de violência e disparidade social quando os marcadores são considerados nas pesquisas diversas. A capacidade de deliberar e fazer escolhas, que constitui a vida em sociedade é obscurecida quando se trata de manter a subordinação das mulheres e de todas as pessoas que fujam ao padrão de correspondência pré-estabelecido nos termos acima mencionados. Compreender e refletir sobre tal diferenciação permite que descubramos que a "destinação" do feminino para a esfera privada e sua subordinação é normatizada e imposta pela cultura androcêntrica, como mostra Simone de Beauvoir em O Segundo Sexo ([1949], 2009), inclusive quando afirma que "não se nasce mulher, torna-se" ([1949], 2009, p. 361). A ideia e condição de mulher conforme ditadas pela cultura androcêntrica não é natural, mas construída culturalmente. Por isso, sem muitos alardes o que está sendo dito é simplesmente que a assimilação da condição de subalternização, de privações, imposições e papéis de gêneros ao corpo e sexo "feminino" não é inata. Essa leitura, sentido e condição atribuída à mulher, e incorporada por essa no mais das vezes, é resultado da vivência no seio das sociedades. Tornar-se mulher nessa condição é incorporar e vivenciar tais códigos e normas sociais sem direitos iguais. Em outras palavras, não é a natureza que marca e estabelece tal "destino-mulher", mas a cultura. A análise de Beauvoir se dirige ao gênero e à condição das mulheres no seio da cultura. Essa questão é inerente à reflexão educacional e se liga diretamente aos direitos humanos, aos direitos fundamentais e sociais iguais e à formação da cidadania, assim como aquela que problematiza o binarismo de gênero e sexo apresentada por Butler. É preciso reconhecer que todas as contribuições, independente das posições em questão, apontam para a mesma conclusão: há uma base cultural não problematizada na visão biológica-natural que funciona como lente a partir da qual as pessoas veem o mundo e impõem certa limitação ou extensão dos chamados direitos humanos. Embora sejamos parte do reino natural, como somos do reino da cultura, já se enxerga o primeiro com os olhos do segundo.

Posto isso, podemos verificar o que está por trás da estigmatização dos estudos de gênero: uma tentativa de sustentação da ideologia de gênero que se esconde atrás de um discurso e pleito pseudocientífico e nada democrático. Somando desinformação, ranço cultural conservador e medo frente ao que ainda não se entende temos o endosso de parte da opinião pública à manutenção dos grilhões de gênero, cujo ultrapassamento torna-se ainda mais urgente. Se a cultura permanece androcêntrica permanece antidemocrática. Mas será que a vida em sociedade nos fornece outras evidências que contrariem as pesquisas e essas questões?

Para testar, vejamos que não faz muito tempo que o código penal brasileiro permitia o assassinato de mulheres casadas que fossem "flagradas" com seus "amantes". Em nome da honra do homem se justificava o assassinato da "adúltera". O fato de que as relações extraconjugais praticadas por homens não tenham originado a mesma proteção ou figura legal se fossem praticadas por mulheres mostra como honra está associada apenas à dignidade masculina. O mesmo se pode confirmar sobre a ideia de pudor no 
contexto naturalizado do assentimento de que homens fiquem sem blusa em público enquanto às mulheres é vedado o direito em favor do tal pudor. A questão aqui não é propriamente o uso ou não de blusas, mas os valores em que se baseiam e aos quais se remetem: de quem seria o pudor preservado? Se prevalece o endosso social aos hábitos e direitos seletivos para homens e mulheres sempre com prejuízo para as últimas não estamos nos referindo a um mero detalhe na organização de nossas sociedades. Dizer que a cultura dominante é ideologicamente androcêntrica significa dizer que o todo da cultura, seus fenômenos, significações, sentidos, lógica, implicações, desdobramentos e imaginário social constituído são ancorados a partir da visão sexista masculinista. Isso ocorre em todos os níveis, desde o arcabouço do julgamento moral vigente aos critérios epistemológicos de produção do conhecimento, passando pelos direitos sociais e as formas de tratamento, reconhecimento e capacidade de autonomia intelectual e existencial.

Como a Cultura, o Direito e Educação estão interligados um avanço isolado das leis em favor das paridades de direitos não é suficiente para mudar essa realidade de diferenças abissais na qualidade de vida das mulheres e de todas as pessoas que fogem aos padrões culturais androcêntricos. Senão, vejamos como em tempos hodiernos parte de uma longa lista de disparidades entre homens e mulheres ainda se mantêm altíssimo índice diário de feminicídio; diferenças salariais em cargos iguais na esfera privada de trabalho; sobrecarga sobre os cuidados com filhos, pais e mães idosos; tratamento desigual nas relações sociais diversas em que as vozes das mulheres e suas posições frente aos diversos assuntos são desqualificadas e infantilizadas; representação política da Câmara Congressual Brasileira com apenas cerca de $9 \%$ de mulheres quando as mesmas compõem $52 \%$ da população; predomínio masculino na ocupação de postos de comando, de formação e acesso a determinadas profissões; empobrecimento maior entre mulheres, em especial as negras e com filhos(as); violência obstétrica; altos índices de estupro, inclusive marital; violência moral; violência doméstica; sobrecarga e responsabilização das mulheres pelas tarefas domésticas - exploração não remunerada que o $\mathrm{IBGE}^{18}$ já demonstrou ser responsável pela redução do tempo que mulheres dispõem para investir em autocuidados e na qualificação profissional. Essas e outras situações estão no bojo da organização da sociedade e da mentalidade cultural. O que é isso senão a ideologia de gênero?

É preciso que a sociedade brasileira esteja atenta ao que prevê a Constituição da República, a saber, que "homens e mulheres são iguais em direitos e obrigações, nos termos desta Constituição" e que "é livre a expressão da atividade intelectual, artística, científica e de comunicação, independentemente de censura ou licença" ${ }^{\prime 19}$. Contra os grilhões impostos ao pensamento e aos corpos é preciso romper com a ideologia de gênero por meio da defesa de uma sociedade inclusiva, democrática, republicana, plural e justa,

\footnotetext{
${ }_{18}$ O IBGE indica que mulheres precisam investir cerca de 20, 8 horas ao serviço de casa por semana enquanto os homens investem apenas cerca de $10 \mathrm{~h}$.

${ }^{19} \mathrm{O}$ Artigo $5^{\circ}$ em sua íntegra encontra-se na Constituição de 1988. Consultada em 02/12/2018. Disponível em http://www.planalto.gov.br/ccivil_03/Leis/L9394.htm
} 
cuja construção só se fará por meio de uma Educação crítica e reflexiva comprometida com valores antisexista, antiandrocêntrica, antiracista.

\section{REFERÊNCIAS}

ALTHUSSER, Louis. Ideologia e aparelhos ideológicos de Estado. 3 ed. - Lisboa: Editorial Presença/Martins Fontes, 1980.

BEAUVOIR, Simone. O segundo sexo. 2 ed. - Rio de Janeiro: Nova Fronteira, [1949] 2009, 2 v.

BORNHEIM. Gerd. Introdução ao Filosofar: o pensamento filosófico em bases existenciais. 8 ed.- São Paulo: Globo, 1989.

BUTLER, Judith. Problemas de Gênero: feminismo como subversão da identidade. $3^{\mathrm{a}}$ ed. - Rio de Janeiro: Civilização Brasileira, [1990] 2010.

CARVALHO, Príscila. A perspectiva dos funcionamentos aplicada a uma concepção ecofeminista identitária. In: A perspectiva dos funcionamentos: por uma abordagem moral mais inclusiva. DIAS, Maria Clara (org.). Rio de Janeiro: Pirilampo, 2015.

CHAUÍ, Marilena. Ideologia e educação. Educação e Pesquisa., São Paulo, v. 42, n. 1, p. 245-257, jan./mar. 2016.

Constituição da República Federativa do Brasil. Promulgação em 1988. Consultada em 02/12/2018. Disponível em http://www.planalto.gov.br/ccivil 03/Leis/L9394.htm

DURKHEIM, Emile. As regras do método sociológico. $4^{a}$ ed. São Paulo: Martins Fontes, 2014.

FOUCAULT, Michel. História da Sexualidade: a vontade de saber. $7^{a}$ ed. Rio de Janeiro: Edições Graal, [1976], 1988, v. 1.

GOUGES, Olympe. Declaração dos Direitos da Mulher e da Cidadã. Florianópolis: Revista Internacional Interdisciplinar Interthesis, V.4, n.1, jan./jun.2007. Consultada em Outubro de 2018. Disponível online em https://periodicos.ufsc.br/index.php/interthesis/article/viewFile/911/10852

IBGE (Instituto Brasileiro de Geografia e Estatística). Pesquisa Nacional por Amostra de Domicílios 2012: Síntese de Indicadores. Rio de Janeiro: IBGE, 2013.

IPEA (Instituto de Pesquisa Econômica Aplicada). Retrato das Desigualdades de Gênero e Raça. Brasilia, Ipea, 2014. Consultado em 27/11/2018. Disponível em http://www.ipea.gov.br/retrato/indicadores.html

JASPERS, Karl. Introdução ao pensamento filosófico. São Paulo: Cultrix, 1971. 
KANT, Immanuel. Fundamentação da Metafísica dos Costumes. Coimbra: Atlântida, 1960.

LDB 9394/1996-2013. Consultada em 27/11/2018. Disponível em http://www.planalto.gov.br/ccivil 03/Leis/L9394.htm A inclusão da consideração com a diversidade étnicoracial se deu em 2013, através da Lei no 12.796.

MARX, Karl. A ideologia Alemã. São Paulo: Boitempo Editorial, 2007.

ROUSSEAU, Jean-Jacques. Emílio, ou Da Educação. 2 ed. São Paulo: Difusão Europeia do Livro, 1973.

RUBIN, Gayle. O tráfico de mulheres: notas sobre a "Economia Política" do Sexo, in Políticas do sexo. Trad. Jamile Pinheiro Dias. São Paulo: Ubu, 2017.

TRACY, Destutt. Elementos da ideologia. Primeira parte. A ideologia propriamente dita. $3^{\text {a }}$ Ed. Tradução de Nuno Melim Disponível em http://cfcul.fc.ul.pt/Seminarios/ElementosIdeologiaTracy.pdf

WOLLSTONECRAFT, Mary. A reivindicação dos direitos da Mulher. São Paulo: Boitempo Editorial, 2016.

Recebido em: 10 de outubro de 2018. Aprovado em: 3 de dezembro de 2018. 